\title{
A RESPONSABILIDADE DAS UNIVERSIDADES PÚBLICAS PELA OFERTA DE CURSOS DE PÓS-GRADUAÇÃO REMUNERADOS: DEBATE ENTRE ADMINISTRATIVISTAS E CONSUMERISTAS
}

\author{
THE RESPONSIBILITY OF THE BRAZILIAN PUBLIC UNIVERSITIES ON \\ THE SUPPL YING OF PAID POSTGRADUATE COURSES: DEBATE \\ BETWEEN AUTHORS FROM PUBLIC AND PRIVATE LAW
}

\author{
${ }^{1}$ Flavia Trentini \\ ${ }^{2}$ Luis Eduardo Brito Scoton
}

\begin{abstract}
RESUMO
O presente artigo discute a responsabilidade de consumo das universidades públicas em razão da oferta ao mercado de cursos de pós-graduação remunerados. Para tanto, parte-se dos debates acerca da aplicabilidade do CDC aos serviços públicos em geral, sendo expostos os diferentes posicionamentos a respeito do tema, apresentados tanto por autores da escola administrativista quanto da escola consumerista. Por fim, aborda-se a possibilidade jurídica de caracterização da universidade pública enquanto fornecedora de serviços, sendo analisados alguns julgados recentes que confirmam esta tese. Foi empregado o método dialético, sob as modalidades de pesquisa bibliográfica e documental. O objetivo é confrontar os principais posicionamentos doutrinários a respeito do tema, de forma a se obter uma síntese a respeito do regime de responsabilidade aplicável às universidades públicas. Conclui- se que a celebração de convênios para oferta de cursos de pósgraduação lato sensu pode implicar em riscos jurídicos para as universidades públicas.
\end{abstract}

Palavras-chave: Responsabilidade, Universidades públicas, Relação de consumo, Cursos de pós-graduação

\begin{abstract}
This article discusses the responsibility of the brazilian public universities on the supplying of paid postgraduate courses to the market. For this end, it analises the applicability of CDC to public services in general, exposing the different positions on the subject, presented by authors both from public and private law. Finally, it describes the legal possibility of characterization of public universities as suppliers of market services and examines some recent court decisions that support this thesis. It was used the dialectical method, in form of bibliographic and documentary research. The aim is contrast the major doctrinal positions on the subject, in order to obtain an overview about the liability regime applicable to public universities. The conclusion is that the agreements for supplying of paid postgraduate courses may entail in legal risks to public universities.
\end{abstract}

Keywords: Liability, Public universities, Consumer contracts, Postgraduate courses

\footnotetext{
${ }^{1}$ Doutora em Direito pela Universidade de São Paulo - USP, São Paulo (Brasil). Professora de Direito pela Universidade de São Paulo - USP, São Paulo (Brasil). E-mail: trentini.sma@terra.com.br

${ }^{2}$ Mestranda em Direito pela Universidade de São Paulo - USP, São Paulo (Brasil).

E-mail: luis.scoton@gmail.com
} 


\section{Introdução}

A aplicação do Código de Defesa do Consumidor (CDC) aos serviços públicos é tema controverso na doutrina e jurisprudência brasileiras. A discussão se funda em saber se as pessoas jurídicas de direito público - e suas concessionárias, permissionárias ou delegatárias estariam incluídas na definição de fornecedor prevista na Lei no 8.078/90.

É certo que o próprio CDC contém dispositivos que direcionam os operadores do direito num sentido de ampla tutela dos usuários de serviços públicos. Entretanto, na prática, a aplicação destes dispositivos tem sido objeto de grandes embates entre administrativistas e consumeristas.

De um lado, há estudiosos do direito administrativo que pregam uma aplicação meramente declaratória ou principiológica - no máximo, subsidiária - do direito do consumidor aos serviços públicos. De outro, alguns adeptos da escola consumerista, que defendem uma aplicação plena das normas do CDC a estes serviços.

A jurisprudência do Superior Tribunal de Justiça (STJ), por sua vez, tem reafirmado que a legislação de consumo somente é aplicável aos serviços públicos impróprios (uti singuli), remunerados mediante preço público ou tarifa. Nesse sentido, os serviços públicos próprios (uti universi), custeados mediante tributos (impostos ou taxas), passam ser regidos por regras próprias, mais condizentes com o regime jurídico de direito público.

Entretanto, como essa discussão está inserida frente aos serviços educacionais prestados por universidades públicas? Qual o regime de responsabilidade aplicável às universidades públicas em razão da oferta de cursos de pós-graduação remunerados? É possível a configuração de relação de consumo entre as universidades públicas e os alunos destes cursos?

O objetivo do presente artigo é responder a estes questionamentos. Para tanto, será debatida a questão da aplicabilidade do CDC aos serviços públicos, sendo expostos os diferentes posicionamentos sobre o tema, apresentados tanto por autores da escola administrativista quanto da escola consumerista. Por fim, será analisado o regime de responsabilidade aplicável à prestação de serviços públicos educacionais, sendo discutida a eventual configuração de relação de consumo entre universidades públicas e alunos de cursos de pós graduação remunerados. 
Foi empregado o método dialético, sob as modalidades de pesquisa bibliográfica e documental. O intuito é confrontar os principais posicionamentos doutrinários sobre o tema, de forma a se obter uma síntese condizente com o ordenamento jurídico pátrio. Espera-se que as conclusões sejam utilizadas pelas universidades públicas, quando da avaliação dos riscos jurídicos envolvidos na celebração de convênios para oferta de cursos de pós-graduação lato sensu.

\section{CDC e serviços públicos}

O principal dispositivo do CDC relacionado à proteção dos usuários de serviços públicos é o artigo 22, cujo caput diz expressamente: "os órgãos públicos, por si ou suas empresas, concessionárias, permissionárias ou sob qualquer outra forma de empreendimento, são obrigados a fornecer serviços adequados, eficientes, seguros e, quanto aos essenciais, contínuos".

Aplicável às pessoas jurídicas de direito público e suas concessionárias, permissionárias ou delegatárias, o objetivo do referido dispositivo foi relembrar os prestadores de serviços públicos sobre o dever de respeito aos princípios do direito administrativo - quais sejam, os princípios da eficiência, da continuidade do serviço e da modicidade das tarifas - . Do ponto de vista legiferante, o caput traz conteúdo pouco inovador, uma vez que a cogência dos referidos princípios já era expressa na própria Constituição Federal.

A evolução ficou por conta da disposição contida em seu parágrafo único, que diz: "Nos casos de descumprimento, total ou parcial, das obrigações referidas neste artigo, serão as pessoas jurídicas compelidas a cumpri-las e a reparar os danos causados, na forma prevista neste código."

A referida norma, ao tratar de regra de responsabilidade civil, inovou ao incluir as pessoas jurídicas de direito público no regime jurídico previsto no CDC, o que ampliou a possibilidade de proteção dos usuários de serviços públicos a partir do uso de alguns institutos protetivos típicos do direito do consumidor, tais como a inversão do ônus da prova, a restituição em dobro de parcelas indevidas, entre outros.

O CDC contém também outros dispositivos aplicáveis aos serviços públicos: o art. 3. ${ }^{\circ}$, caput, inclui no conceito de fornecedor as pessoas jurídicas de direito público; o art. 4. ${ }^{\circ}$, 
VII, elege como princípio da Política Nacional das Relações de Consumo a racionalização e melhoria dos serviços públicos; o art.6. ${ }^{\circ}, \mathrm{X}$, declara o direito básico do consumidor à uma prestação adequada e eficaz dos serviços públicos em geral; o artigo 56, incisos I, VI, VIII e XI, do CDC, trata das sanções administrativas aplicáveis aos concessionários e delegatários de serviços públicos (PASQUALOTTO, 1992, p. 1116).

Todavia, o âmbito de aplicação dessas normas tem sido, de certa forma, restringido. Embora passados quase vinte e cinco anos desde a edição do CDC, ainda há controvérsias sobre a aplicabilidade de suas normas aos serviços públicos.

Em geral, costumam ser identificados quatro diferentes posicionamentos a respeito do tema: a) os que fogem dos principais problemas relativos à aplicabilidade do CDC aos serviços públicos; b) os que defendem uma interpretação extensiva; c) os que propõem uma interpretação extensiva mitigada; e d) os que defendem uma interpretação restritiva do Código de Defesa do Consumidor (MACEDO JÚNIOR, 2002, p. 240).

Ao comentar a referida classificação, Gustavo Soares Aguiar (2010, p. 277) explica que:

No primeiro posicionamento, inserem-se os doutrinadores que não se ocupam de definir a extensão do âmbito de incidência do CDC sobre os serviços públicos, ou seja, não se preocupam em dizer se sobre esses recai apenas o disposto no art. 22 da Lei n 8.078/90 ou todo o conteúdo do Código. Não indicam, portanto, quais serviços públicos merecem proteção nem as normas do CDC a eles aplicáveis.

Pelo segundo ponto de vista, ao que se atribui uma interpretação extensiva, fica estabelecido que o Código de Defesa do Consumidor aplica-se a todos os serviços públicos, sejam eles coletivos (uti universi) ou individuais (uti singuli).[...]

A terceira opinião é a do grupo de autores que desenvolve uma interpretação extensiva mitigada. Nela, fica assentado que o CDC apenas tem incidência sobre serviços custeados por taxa ou tarifa, porque somente essas duas formas de receita consubstanciam-se num meio de remuneração específica pela prestação do serviço. Os serviços públicos gerais, portanto, não integrariam o âmbito de proteção do código, já que seu custeio faz-se por meio da aplicação dos recursos arrecadados a título de impostos, que não constituiriam propriamente uma remuneração.

A quarta posição, por fim, é a que se denomina restritiva [...]. Nesse posicionamento, fica assentado que apenas os serviços públicos individuais (uti singuli) e retribuídos por preço público ou tarifa são objeto de tutela do Código de Defesa do Consumidor. 
Esta última posição, que defende a interpretação restritiva, esta sendo adotada pela jurisprudência majoritária do STJ, conforme demonstrado no julgamento do Recurso Especial $\mathrm{n}^{\mathrm{o}}$ 754.784/PR, relatado pela Ministra Eliana Calmon (STJ, 2004):

\section{ADMINISTRATIVO - SERVIÇO PÚBLICO - CONCEDIDO - ENERGIA ELÉTRICA - INADIMPLÊNCIA.}

1. Os serviços públicos podem ser próprios e gerais, sem possibilidade de identificação dos destinatários. São financiados pelos tributos e prestados pelo próprio Estado, tais como segurança pública, saúde, educação, etc. Podem ser também impróprios e individuais, com destinatários determinados ou determináveis. Neste caso, têm uso específico e mensurável, tais como os serviços de telefone, água e energia elétrica. 2. Os serviços públicos impróprios podem ser prestados por órgãos da administração pública indireta ou, modernamente, por delegação, como previsto na CF (art. 175). São regulados pela Lei 8.987/95, que dispõe sobre a concessão e permissão dos serviços público.3. Os serviços prestados por concessionárias são remunerados por tarifa, sendo facultativa a sua utilização, que é regida pelo CDC, o que a diferencia da taxa, esta, remuneração do serviço público próprio. 4. Os serviços públicos essenciais, remunerados por tarifa, porque prestados por concessionárias do serviço, podem sofrer interrupção quando há inadimplência, como previsto no art. $6^{\circ}$, $\S 3^{\circ}$, II, da Lei 8.987/95, Exige- se, entretanto, que a interrupção seja antecedida por aviso, existindo na Lei 9.427/97, que criou a ANEEL, idêntica previsão. 5. A continuidade do serviço, sem o efetivo pagamento, quebra o princípio da igualdade da partes e ocasiona o enriquecimento sem causa, repudiado pelo Direito (arts. 42 e 71 do CDC, em interpretação conjunta). 6. Recurso especial provido.

\section{Posição semelhante é defendida por José Geraldo Brito Filomeno (GRINOVER et}

alli, 2011, p. 53), a respeito do conceito de fornecedor estabelecido no Anteprojeto do CDC:

E, efetivamente, fala o $\S 2^{\circ}$ do art. $3^{\circ}$ do Código Brasileiro de Defesa do Consumidor em "serviço" como sendo "qualquer atividade fornecida no mercado de consumo, mediante remuneração, inclusive as de natureza bancária, financeira, de crédito e securitária, salvo as decorrentes das relações de caráter trabalhista".

Importante salientar-se, desde logo, que aí não se inserem os "tributos", em geral, ou "taxas" e "contribuições de melhoria", especialmente, que se inserem no âmbito das relações de natureza tributária.

Não se há de confundir, por outro lado, referidos tributos com as "tarifas", estas sim, inseridas no contexto dos "serviços" ou, mais particularmente, "preço público", pelos "serviços" prestados diretamente pelo poder público, ou então mediante sua concessão ou permissão pela iniciativa privada.

$\mathrm{O}$ que se pretende dizer é que o "contribuinte" não se confunde com "consumidor", já que no primeiro caso o que subsiste é uma relação de Direito Tributário, inserida a prestação de serviços públicos, genérica e universalmente considerada, na atividade precípua do estado, ou seja, a persecução do bem comum. 


\section{A posição administrativista: a aplicação do regime jurídico de direito público aos serviços públicos}

Não obstante, existe entre os doutrinadores uma quinta posição. Este quinto posicionamento, de âmbito tipicamente administrativista, defende que haveria uma manifesta distinção entre os conceitos de usuário de serviço público e de consumidor, o que implicaria em uma aplicação pontual e meramente declaratória do CDC aos serviços públicos.

O referido posicionamento é defendido por César Augusto Guimarães Pereira (2008). É também encontrado na opinião de autores como Marçal Justen Filho (2003;2005), Tani Maria Wurster (2006) e Maria Cristina Cesar de Oliveira (2003), que a princípio se declaram favoráveis à aplicação do CDC aos serviços públicos, mas que em casos específicos defendem a sobrevalência do regime jurídico de direito público às normas do direito do consumidor.

Para estes autores, os conceitos de consumidor e usuário partiriam de matrizes constitucionais distintas. O consumidor seria um agente da economia de mercado (art. 170, V, da Constituição), enquanto o usuário seria destinatário de uma prestação que, por definição, estaria fora do mercado (art. 175 da Constituição). O consumidor teria uma posição jurídica caracterizada pela titularidade de direitos individuais subjetivos. Já o usuário seria titular de direitos subjetivos funcionalizados. Por esta razão, o usuário teria direitos em relação à criação e organização do serviço completamente incompatíveis com a posição jurídica de um consumidor (PEREIRA, 2008, p. 358).

Segundo César Augusto Guimarães Pereira (2008, p. 367-372), a aplicação do CDC aos serviços públicos será possível apenas mediante caráter provisório - nos espaços de liberdade (lacunas) deixados pelo legislador - e como veículo de normas de direito administrativo, sobrevalendo sempre a disciplina de direito público, em caso de divergência:

Desse modo, a disciplina própria do consumidor, contida no CDC, somente é aplicável aos usuários de serviço público (a) nos espaços de liberdade deixados pela regulamentação do serviço público e (b) provisoriamente, enquanto não editadas as leis pertinentes ao serviço público em questão (pelo ente político que titulariza o serviço ou, no caso do art. 22, XXVII, da Constituição, pela União).

$[\ldots]$

A percepção de que, na maior parte dos casos - afinal, os espaços de liberdade em que há a aplicação própria do CDC são excepcionais -, o CDC ou é aplicado (limitadamente) como norma de Direito Administrativo ou é invocado (também limitadamente) com finalidade meramente declaratória ou 
confirmatória do regime de direito público destina-se a evitar equívocos de interpretação ou aplicação. A despeito das reservas doutrinárias, especialmente dos autores mais fortemente vinculados ao direito público, a jurisprudência tende a dar ampla e irrestrita aplicação ao CDC relativamente ao serviço público. A constatação aqui enunciada pretende demonstrar que essa aplicação ou é equivocada - quando contraria o regime público - ou é apenas aparente: a disciplina aplicada é, na realidade, a que deriva do próprio direito público.

No mesmo sentido Marçal Justen Filho (2005, p. 492), que defende a preponderância do direito administrativo sobre o direito do consumidor, prevalecendo o regime jurídico de direito público às regras de responsabilidade civil e de tutela processual coletiva previstas no CDC. Segundo o autor, o regime de direito público seria indispensável para assegurar a continuidade, a generalidade, a adequação do serviço público.A preponderância do regime jurídico de direito público é também defendida pela juíza Tani Maria Wurster (2006), para quem princípios da razoabilidade, da indisponibilidade e da supremacia do interesse público devem ser respeitados em sua integralidade:

Dada a complexidade de bens jurídicos a serem protegidos segundo o modelo de Estado proposto pela Constituição Federal, é insuficiente afirmar que o Código de Defesa do Consumidor se aplica, indistintamente e automaticamente, em face da prestação de serviços públicos. A Lei 8.078/90 e a Lei 8.987/95, com vistas à regulamentação dos arts. 170, V, e 175 da Constituição Federal, reconheceram pontos de convergência entre a defesa do consumidor e a prestação de serviços públicos. A compatibilização dos sistemas privado, de defesa do consumidor, e público, da prestação dos serviços públicos, naquilo que são incompatíveis, impõe a utilização do princípio da razoabilidade, a ser verificado caso a caso.

Os princípios da supremacia e da indisponibilidade do interesse público, no entanto, determinam que o regime de Direito Administrativo prepondera sobre o Direito do Consumidor. Neste caso, importante invocar, ainda, os princípios da alteração unilateral das condições da prestação do serviço, da vinculação ao edital no caso de licitação e da manutenção do equilíbrio econômico-financeiro para justificar a posição adotada.

Já Maria Cristina Cesar de Oliveira (2003) defende a aplicação do CDC apenas aos serviços públicos delegados. Na opinião da autora, quando há prestação direta do serviço público pelo Estado, deve-se atribuir caráter meramente declaratório às normas estabelecidas no $\mathrm{CDC}$, servindo este apenas de reforço aos próprios princípios administrativos que regem a prestação do serviço. 
Sendo assim, segundo o pensamento administrativista, os direitos dos usuários de serviços públicos deveriam ser tutelados pelas Leis Complementares de âmbito administrativo previstas no próprio texto constitucional, a exemplo: a Lei de Concessões (Lei nº 8.987/1995) e a Lei de Defesa dos Usuários de Serviços Públicos (cujo projeto se encontra em tramitação na Câmara Federal).

Entretanto, tais instrumentos não são hierarquicamente superiores ao $\mathrm{CDC}$ e tampouco tem se mostrado suficientes para uma adequada tutela dos usuários de serviços públicos.

\section{A posição consumerista: o ente público como fornecedor de serviços}

A visão administrativista apresentada no tópico anterior contrasta com a opinião da maioria dos estudiosos da área do direito do consumidor. Em geral, os autores consumeristas resgatam o caráter público e de interesse social das normas contidas no $\mathrm{CDC}$, e defendem a sua aplicabilidade, em maior ou menor grau, aos serviços públicos. Para estes, os prestadores de serviços públicos, inclusive as universidades públicas, podem estar abarcados no amplo conceito de fornecedor previsto no artigo $3^{\circ}, \S 2^{\circ}$.

De acordo com Leonardo Roscoe Bessa, “não há duvida a respeito da possibilidade de incidência do CDC aos serviços públicos” (BENJAMIN; MARQUES; BESSA, 2012, p. 216). Segundo ele, a melhor posição sobre as espécies de serviços públicos que estão sob a disciplina do CDC deve levar em consideração dois aspectos: a) a remuneração específica do serviço; e b) a noção de mercado de consumo.

Sobre a remuneração específica pelo serviço, o autor explica que esta poderá ser direta ou indireta. Todavia, exige-se que seja atividade desenvolvida no mercado de consumo (BENJAMIN; MARQUES; BESSA, 2012, p. 216-217):

\footnotetext{
Não são próprios do mercado os serviços do estado relativos à segurança, prestação jurisdicional, iluminação pública, nem mesmo sua obrigatória atuação no campo da educação e saúde, não por ausência de remuneração indireta - já que os impostos cumprem este requisito - mas, repita-se, porque estão fora do mercado.

Deve, portanto, haver certa correspondência entre o valor pago e o serviço prestado (relação econômica de troca). O serviço, portanto, deve ser divisível e mensurável individualmente. Simplificando, deve haver correlação entre o que se paga e o que se recebe (ou se deveria receber). Só é possível falar em equilíbrio da relação e houver esse caráter sinalagmático.
} 


\begin{abstract}
[...]
Em relação à natureza da remuneração, não importa se é taxa ou tarifa (preço público): importa haver certa correlação entre o pagamento e o serviço prestado. Aliás, a noção da espécie tributária taxa baseia-se justamente no seu caráter sinalagmático [...].

A tese defendida pela doutrina no sentido de que a cobrança de taxa espécie tributária - afastaria a incidência do CDC conduz a perplexidades. O pagamento do serviço relativo ao fornecimento de água ora é considerado preço público, ora é considerado taxa pela jurisprudência. Tais incertezas não devem afetar a certeza de ser um serviço oferecido profissionalmente (com habitualidade), divisível, mensurável, com remuneração específica, fatores que realmente devem ser considerados para exame da aplicação do CDC.
\end{abstract}

Além disso, o mesmo defende que as classificações doutrinárias dos serviços públicos (uti singuli ou uti universi), em razão de sua equivocidade, não devem ser utilizadas para a análise da incidência ou não do CDC. A frágil classificação daria lugar, portanto, à noção de mercado de consumo (BENJAMIN; MARQUES; BESSA, 2012, p. 216):

O CDC cuida, em síntese, de situações de vulnerabilidades geradas pelo mercado de consumo. O critério, portanto, para delimitar quais serviços públicos estão sujeitos à Lei 8.078/1990 é a compreensão do mercado de consumo, vale dizer, de atividades econômicas próprias do ciclo de produção e circulação dos produtos ou de fornecimento de serviços. [...]

São serviços públicos sujeitos ao CDC tanto os referidos pelo art. 173 como aqueles indicados no art. 175 da Constituição Federal, pois nos dois casos são atividades desenvolvidas no mercado de consumo. Estão sob a disciplina do CDC, portanto, os serviços de telefonia, transporte coletivo, energia elétrica, água, por atenderem aos pressupostos indicados, independentemente, destaque-se, da natureza da remuneração.

Bruno Miragem (2014, p. 183), por sua vez, defende a aplicação do CDC sempre que houver a presença do consumidor como agente de uma relação de aquisição remunerada do serviço público, individualmente e de modo mensurável. De acordo com o autor, a distinção entre consumidor e usuário, jamais poderá se dar com a finalidade de afastar a incidência do CDC de uma determinada relação de consumo. O critério para delimitação do âmbito de incidência do CDC deve ser, portanto, determinado segundo as próprias disposições deste, a partir da identificação da relação de consumo caso a caso.

Já Cláudia Lima Marques (2011, p. 586) defende uma interpretação mais restritiva, semelhante à sustentada pelo STJ, e esclarece que "até hoje, a noção de diálogo das fontes não teve muito sucesso em matéria de serviços públicos e as normas do CDC não conseguiram reequilibrar, na prática, esta relação." 
Contudo, a autora sustenta que a nova disciplina dos contratos de fornecimento de serviços públicos deverá conciliar as imposições do direito constitucional, com a proteção do consumidor e as prerrogativas administrativas (MARQUES, 2011, p. 586).

Os autores consumeristas defendem, portanto, a aplicabilidade das normas de direito do consumidor aos serviços públicos em razão do próprio caráter público presente nas normas do CDC. Além disso, afirmam que o conceito de interesse público não se confunde com o interesse do Estado enquanto pessoa jurídica, devendo preponderar o interesse do cidadão enquanto sujeito de direito.

Nesse sentido, em se tratando de serviço público de prestação constitucional não compulsória, fornecido no mercado de consumo, mediante remuneração, é possível a caracterização da relação de consumo, de acordo com os limites previstos no próprio CDC, independentemente da aplicação do regime jurídico de direito público às prestadoras.

\section{A universidade pública enquanto fornecedora: possibilidade jurídica}

Especificamente quanto à possibilidade de enquadramento do prestador de serviços educacionais na categoria de fornecedor prevista no CDC, há de se fazer uma análise caso a caso. Isto porque a Constituição Federal prevê o direito à educação como um "feixe de direitos", portanto, como um conceito jurídico amplo e complexo.

Sendo assim, o conceito de educação pode ser tanto abrangente (preparação para o trabalho e para a cidadania; desenvolvimento das aptidões, potencialidades e da própria personalidade do educando), quanto restrito (ensino, educação formal e instrução). De fato, do ponto de vista jurídico, a educação pode ser tratada simultaneamente como um direito, como um dever e como um serviço (ABMP, 2013, p. 76-85).

A Constituição Brasileira, outrossim, trata a educação como um serviço de natureza tipicamente pública. Tal natureza pública não advém de um eventual monopólio do Estado, mas de uma prestação que busca transcender o plano individual. Sendo assim, os serviços educacionais serão sempre "serviços públicos", em sua acepção genérica. Isto não quer dizer, todavia, que se tratem sempre de serviços prestados pelo Estado. Lívio Goellner Goron (2012, p. 193), explica tratar-se de dois serviços distintos, enfeixados sob o mesmo rótulo: um é o serviço educacional prestado diretamente pelas instituições do Estado (serviço 
público em sentido estrito); outro, o serviço educacional ministrado por instituições privadas (serviço de utilidade pública).

O art. 206, III, da CF/1988, aliás, garante a pluralidade de ideias e a coexistência entre instituições públicas e privadas, tanto no ensino básico, fundamental e médio, quanto no ensino superior. É essa coexistência que permite a incidência do CDC aos contratos de prestação de serviços educacionais. Trata-se de um serviço de caráter público, mas não exclusivo (GORON, 2012, p. 193):

Com efeito, o texto constitucional abriu o ensino à iniciativa privada, submetendo a atividade das instituições particulares de ensino à autorização e à avaliação de qualidade do Poder Público e à observância de normas gerais de educação (art. 209, caput, I e II, e art. 206, VII, da CF/1988). A Constituição brasileira resguardou aos agentes privados, portanto, um papel expressivo no que concerne aos serviços educacionais. Cumpre notar que o papel da iniciativa privada amplia-se gradativamente de acordo com a progressão dos níveis de ensino. No ensino fundamental a oferta gratuita de ensino pelo Estado é reputada obrigatória para todos aqueles que não tenham condições de custeá-lo (art. 208, I, da CF/1988); no ensino médio, colocando-se um passo atrás, a Constituição contempla a progressiva universalização do acesso, como um mandamento de otimização (inc. II); na esfera do ensino superior, por último, não há previsão acerca de uma oferta estatal universal. A iniciativa privada atua, em termos gerais, no espaço residual dessa presença do Estado: com efeito, no ensino fundamental e médio existe um claro predomínio de alunos que frequentam instituições públicas, ao passo que no ensino superior os alunos matriculados em entidades particulares superam, numericamente, os de universidades públicas.

A aplicação do CDC aos serviços educacionais prestados por entidades privadas é indiscutível. Esta aplicabilidade tem sido reafirmada pelo Supremo Tribunal Federal (STF) em vários de seus julgados. Tome-se como exemplo as Ações Diretas de Inconstitucionalidade $\mathrm{n}^{\circ} 1007$ e $\mathrm{n}^{\circ} 1042$, nas quais os relatores entenderam ser de competência da União, e não dos Estados, a intervenção estatal nos contratos de prestação de ensino, sempre mediante a edição de normas de defesa do consumidor para a proteção dos usuários dos serviços educacionais de utilidade pública.

Já nos casos em que o serviço educacional é prestado por entidades públicas, torna-se indispensável estabelecer uma distinção entre os serviços públicos educacionais próprios e impróprios. Sendo assim, tanto o ensino básico, fundamental e médio, quanto o ensino superior, quando prestados diretamente pelo Estado, classificam-se entre os serviços públicos educacionais próprios, ou seja, tratam-se de serviços administrados pelo Estado, 
custeados mediante impostos e pagos pelo contribuinte em geral. Nestes casos, não há a possibilidade de incidência do CDC, vez que não há remuneração específica sobre os serviços e que estes não estão disponibilizados no mercado de consumo.

O mesmo ocorre quanto aos cursos de pós-graduação ofertados gratuitamente por universidades públicas. Tratam-se, em geral, de cursos de pós-graduação stricto sensu voltados especificamente à formação de docentes e pesquisadores, ou ao aprimoramento de servidores públicos, e que, em razão de seus fins, estão excluídos do mercado de consumo.

Não obstante, tem se tornado bastante comum a oferta de cursos pagos de pósgraduação lato sensu (especializações) por estas instituições. Tais cursos podem ser oferecidos de forma individual pela universidade ou por meio de parcerias, ou seja, a partir da celebração de convênios entre fundações educacionais de apoio, criadas por professores das universidades, e as respectivas unidades públicas de ensino.

As fundações são pessoas jurídicas de tipo especial, compostas por bens arrecadados e personificados, destinados à realização de fins socialmente úteis (GOMES, 1979, p. 217). Para que adquiram personalidade jurídica, prescindem da existência de: a) um patrimônio afetado; b) destinado a fins específicos; c) administrados de acordo com um estatuto; d) registrado junto ao Cartório de Registro Civil das Pessoas Jurídicas; e e) submetido à aprovação e fiscalização do Ministério Público (TARTUCE, 2011, p. 126).

Já as fundações educacionais "são pessoas jurídicas, formadas por ato volitivo do instituidor, seja por escritura pública ou testamento (e, sendo pública, através de lei), mediante a destinação de um patrimônio voltado à promoção do ensino, da pesquisa e da difusão do conhecimento." (MORATO ; BITTAR, 2003, p. 144).

Grande parte destas fundações tem por escopo principal o oferecimento de serviços educacionais, técnicos e científicos ao mercado, facilitados mediante a celebração de convênios junto a instituições públicas. Dessa forma, as universidades públicas poderão ser responsabilizadas por eventuais falhas na prestação dos serviços.

Em geral, são promovidos arranjos contratuais triangulares, em que são contratantes os particulares, a própria fundação e as universidades públicas, estas responsáveis pela emissão de certificados, bem como pela atribuição de credibilidade aos serviços. Sendo assim, tais convênios têm resultado em relações obrigacionais complexas, nas quais "o judiciário, em determinadas situações, equipara o prestador ao Estado, em outras frisa sua qualidade de 
mero delegatário, submetido ao controle finalístico do Estado; em outras, ainda, sequer o reconhece como delegado" (ABMP, 2013, P. 84).

E assim, por prestarem serviços educacionais impróprios - está ausente um dos elementos do conceito de serviço público, que é a gestão, direta ou indireta, pelo Estado -, oferecidos mediante remuneração (mensalidade), tais fundações se submetem às normas de proteção e defesa do consumidor, independentemente do regime jurídico escolhido para sua criação (público ou privado).

Nesse contexto, as universidades públicas figuram como fornecedoras solidárias, dado o convênio existente junto às fundações, cujo contrato, ainda que dotado de cláusula excludente de responsabilidade, não poderá ser oposto a terceiros (consumidores), em razão do seu caráter particular. Nesse sentido, Nina Beatriz Stocco Ranieri destaca que (apud ABMP, 2013, p. 83):

Ao consumidor de serviços educacionais a legislação específica garante proteção em hipóteses, v.g., de serviço defeituoso (art. 14 e parágrafos), nas quais o fornecedor de serviços responde, independentemente da existência de culpa, pela reparação dos danos causados aos consumidores por defeitos na prestação dos serviços, considerados defeitos aqueles decorrentes do modo de fornecimento (ensino inadequado ou insuficiente, por exemplo) ou da época em que foram fornecidos (aulas ministradas fora do período determinado para tanto) (art. 14, I e III). Nesses casos, é de notar que todas as vítimas do evento se equiparam a consumidores o que, numa hipótese ampliada, significa dizer que os defeitos no oferecimento do ensino alcançariam todos aqueles sujeitos à atuação do profissional mal formado (art. 17).

A mesma situação se verifica em relação a vícios de qualidade no ensino, decorrentes da disparidade com as indicações constantes da oferta ou mensagem publicitária (art. 20) responsabilizam o fornecedor. A informação adequada e clara sobre os serviços, a proteção contra a publicidade enganosa e abusiva, a efetiva prevenção e reparação dos danos patrimoniais e morais, individuais, coletivos e difusos são direitos básicos do consumidor (art. $6^{\circ}$ ). Para a Educação Superior, em particular, o art. $47, \S 1^{\circ}$, da LDB exige que as instituições de ensino, antes de cada período letivo, informem aos interessados os programas dos cursos e demais componentes curriculares, sua duração, requisitos, qualificação dos professores, recursos disponíveis, e critérios de avaliação, obrigando-se a cumprir as respectivas condições.

Há, todavia, autores administrativistas que argumentam pela impossibilidade de figuração da universidade enquanto fornecedora no caso em questão, em razão da aplicação do regime jurídico de direito público ao relacionamento entre universidades públicas e entes externos (BARBOSA, 2003, p. 272-273):

Justifica-se a aplicação do direito público a este relacionamento por uma série de razões, as quais apresentamos resumidamente: (i) o direito 
constitucional positivo outorgou autonomia às universidades, a qual foi regulada pela LDB como forma de realizar o interesse público; (ii) a universidade pública, na maioria das vezes (para não dizer em todas as situações), possui natureza autárquica, consistindo em pessoa jurídica de direito público; (iii) para que as universidades públicas pudessem gozar da autonomia constitucional atribuída às universidades em geral, inclusive às privadas (regidas pelo direito civil em diversos aspectos), foi necessário o estabelecimento de prerrogativas específicas, pelas quais, na maioria das vezes, derrogam-se regras gerais de direito administrativo normalmente aplicáveis à administração pública; (iv) as atividades objeto de relacionamento são de interesse público, pois consistem na verdadeira razão de existência tanto da universidade pública, quanto das imunidades e privilégios constitucional ou legalmente assegurados às fundações educacionais.

Contudo, conforme defendem os autores consumeristas, a autonomia universitária e o regime jurídico de direito público, por si, não podem ser utilizados para afastar o âmbito de incidência do CDC sobre os serviços públicos educacionais. Nina Beatriz Stocco Ranieri (2013, p. 205), ao falar dos limites da autonomia universitária, também ressalta que :

Ensino e pesquisa pressupõem liberdade. Por isso a universidade é autônoma e por isso o legislador constituinte confirmou-lhe prerrogativas essenciais ao exercício desta liberdade, exigindo que aqueles sejam estendidos à sociedade.

Não se trata, porém, de ser autônomo em relação ao estado, ausente qualquer controle, mas de ser autônomo dentro dos limites fixados pelo ordenamento constitucional tendo em vista os fins do Estado, os quais a universidade, como órgão público, deve necessariamente perseguir.

Mesmo a defesa das garantias institucionais não deve ser tomada pela defesa de privilégios, característica do corporativismo moderno que preconiza a organização de instituições como grupos de interesse individuais, sem levar em conta o contexto social mais amplo onde atuam, o que deturparia a essência da universidade.

A qualidade e a relevância do ensino e da pesquisa produzidas na universidade configuram a essência do limite institucional da autonomia. Os parâmetros constitucionais, por sua vez, estabelecem os seus limites jurídicos.

É importante ressaltar, ainda, quanto às controvérsias erigidas em relação ao regime jurídico aplicável às universidades públicas, que tanto a responsabilidade civil baseada na teoria do risco administrativo (responsabilidade civil do Estado), quanto a responsabilidade civil baseada na teoria do risco do empreendimento (responsabilidade pelo vício do serviço) serão aplicáveis em sua forma objetiva, ou seja, em ambos os casos as universidades poderão ser responsabilizadas independentemente da existência de culpa (CAVALIERI FILHO, 2007, p. 228). 
As diferenças se darão em dois aspectos: a) quanto à extensão do valor indenizatório (geralmente maior na responsabilidade civil de consumo); e b) quanto ao grau de tolerância em relação à ocorrência e extensão do dano. Como regra geral, a responsabilidade civil do Estado pressupõe a ocorrência de um dano específico (que atinja a um ou a alguns membros da coletividade) e anormal (que ultrapasse os inconvenientes comuns à atuação estatal). Já a responsabilidade pelo vício do serviço pressupõe a ocorrência de qualquer dano econômico, mediante simples comprovação do respectivo nexo de causalidade (DI PIETRO, 2011, p. 401).

Além disso, o CDC, por tutelar relações de vulnerabilidade entre fornecedores e consumidores, prevê uma série de normas protetivas a estes últimos, como por exemplo: regras de competência relativa de foro; possibilidade de inversão do ônus da prova; direito à indenização em dobro; entre outras.

Sendo assim, a jurisprudência tem declarado a responsabilidade solidária da universidade pública por vícios ou falhas na prestação de cursos de pós-graduação conveniados. Nesse sentido, destacam-se recentes julgamentos proferidos pelo Tribunal de Justiça do Estado de São Paulo (TJSP) e pelo Tribunal de Justiça do Distrito Federal e dos Territórios (TJDFT).

Nas decisões da Apelação n 2012.0000464534, de 10 de setembro de 2012, e do Recurso Inominado n $^{\mathbf{0}}$ 2013.0000014459, de 20 de junho de 2013, o Tribunal de Justiça do Estado de São Paulo deu provimento aos pedidos de indenização por danos morais e materiais formulados por alunos de pós-graduação de instituição de ensino particular conveniada à uma universidade pública. Os alunos alegaram ter sofrido danos após a suspensão do convênio entre esta instituição e a universidade publica.

Os discentes sustentaram que houve publicidade enganosa por parte das instituições, além de vício na prestação do serviço, não havendo mais interesse na continuidade do curso, sobretudo após a suspensão da possibilidade de emissão dos certificados pela universidade pública. Esta, por sua vez, alegou ilegitimidade passiva para figurar nas causas, além de culpa exclusiva da instituição particular quanto ao distrato, ocorrido em razão da falta de repasses financeiros que estavam previstos no convênio. Em ambos os casos, os julgadores entenderam que a universidade pública era responsável solidária pelas falhas na prestação do serviço.

Nos Embargos Declaratórios no 20101210011074-ACJ, de 14 de fevereiro de 2012, o Tribunal de Justiça do Distrito Federal e dos Territórios também reconheceu a 
responsabilidade solidária entre ma universidade pública do Estado do Tocantins e uma instituição de ensino privada. Ambas as instituições haviam celebrado convênio para oferecimento de cursos de graduação à distância $(\mathrm{EaD})$. Ao final do processo, o tribunal acolheu o pedido de indenização por danos morais formulado pela autora, que se viu prejudicada em razão da demora injustificada na emissão de documentos necessários à sua transferência para outra instituição de ensino.

\section{Conclusão}

A discussão sobre a aplicabilidade do CDC aos serviços públicos remete a um corrente embate entre administrativistas e consumeristas. A posição administrativista defende que haveria uma manifesta distinção entre os conceitos de consumidor e de usuário de serviço público. Segundo esta visão, o regime jurídico de direito público afastaria o âmbito de incidência do CDC sobre os serviços públicos. Já a posição consumerista parte do amplo conceito de fornecedor previsto no CDC - norma de ordem pública e interesse social - para incluir os entes públicos como prestadores de serviços em uma relação de consumo.

$\mathrm{O}$ referido debate também pode ser aplicado frente à discussão quanto ao regime de responsabilidade aplicável às instituições públicas e privadas prestadoras de serviços educacionais. Pode-se dizer que o CDC é aplicável a todos os contratos de prestação de serviços educacionais oferecidos por entidades particulares. Contudo, quando tal prestação for realizada por universidade pública, tal análise deve ser feita caso a caso.

Embora, em geral, sejam responsáveis pelo oferecimento de serviços públicos educacionais próprios, disponibilizados extramercado, as universidades públicas têm celebrado nos últimos anos alguns convênios junto a fundações educacionais de apoio, para o oferecimento de cursos de pós-graduação lato sensu remunerados. Neste caso, trata-se de oferecimento de serviço educacional impróprio, sendo a universidade pública solidariamente responsável por eventuais falhas na prestação do serviço.

Tal possibilidade de responsabilização solidária das universidades públicas em razão oferta de cursos de pós-graduação remunerados tem sido reafirmada por alguns tribunais pátrios, o que pode representar risco jurídico para as instituições públicas de ensino superior que costumam celebrar estes tipos de convênios. 


\section{Referências bibliográficas}

ABMP (Org.). ASSOCIAÇÃO BRASILEIRA DE MAGISTRADOS, PROMOTORES DE JUSTIÇA E DEFENSORES PÚBLICOS DA INFÂNCIA E JUVENTUDE. Justiça pela qualidade na educação. São Paulo : Saraiva, 2013.

AGUIAR, Gustavo Soares. Aplicabilidade do Código de Defesa do Consumidor aos serviços públicos. In: PEREIRA, Cláudia Fernanda de Oliveira (Coord.). O novo direito administrativo brasileiro: o público e o privado em debate. vol.2. Belo Horizonte : Fórum, 2010 .

BARBOSA, Frederico da Silveira. Relacionamento de fundações educacionais com as universidades públicas. In: PANTALEÃO, Leonardo (Org.). Fundações Educacionais. São Paulo : Atlas, 2003.

BENJAMIN, Antônio Herman V.; MARQUES, Claudia Lima; BESSA, Leonardo Roscoe. Manual de direito do consumidor. 4.ed. São Paulo : RT, 2012.

CAVALIERI FILHO, Sergio. Programa de responsabilidade civil. 7. ed. São Paulo : Atlas, 2007.

DI PIETRO, Maria Sylvia Zanella. Responsabilidade civil do Estado. In: RODRIGUES JUNIOR, Otavio Luiz et alli (coords.). Responsabilidade civil contemporânea: em homenagem a Silvio de Salvo Venosa. São Paulo : Atlas, 2011.

GOMES, Orlando. Introdução ao direito civil. 6.ed. Rio de Janeiro : Forense, 1979.

GORON, Lívio Goellner. Serviços educacionais e direito do consumidor. In: Direito \& Justiça, v. 38, n. 2, p. 192-199, jul./dez. 2012.

GRINOVER, Ada Pellegrini et alli. Código Brasileiro de Defesa do Consumidor: comentado pelos autores do anteprojeto. 10 ed. vol. 1. Rio de Janeiro : Forense, 2011.

JUSTEN FILHO, Marçal. Curso de direito administrativo. São Paulo: Saraiva, 2005.

Teoria geral das concessões de serviço público. São Paulo: Dialética, 2003.

MACEDO JÚNIOR, Ronaldo Porto. A proteção do usuário de serviços públicos: a perspectiva do direito do consumidor. In: SUNDFELD, Carlos Ari (Coord.) Direito administrativo econômico. São Paulo : Malheiros, 2002.

MARQUES, Cláudia Lima. Contratos no Código de Defesa do Consumidor. 6.ed. São Paulo : RT, 2011.

MIRAGEM, Bruno. A regulação do serviço público de energia elétrica e o direito do consumidor. In: DI PIETRO, Maria Sylvia Zanella; SUNDFELD, Carlos Ari (Orgs.). Doutrinas essenciais de direito administrativo. vol. 6. São Paulo : RT, 2012, p. 1163-1200.

Curso de direito do consumidor. 5.ed. São Paulo : RT, 2014.

MORATO, Antônio Carlos; BITTAR, Eduardo Carlos Bianca. Das fundações educacionais. In: PANTALEÃO, Leonardo (Org.). Fundações Educacionais. São Paulo : Atlas, 2003. 
OLIVEIRA., Maria Cristina Cesar de. O Código de Defesa do Consumidor e a Administração Pública. Interesse Público. Porto Alegre Notadez. ano 5, n. 22, nov./dez. 2003.

PASQUALOTTO, Adalberto. Os serviços públicos no Código de Defesa do Consumidor. In: DI PIETRO, Maria Sylvia Zanella; SUNDFELD, Carlos Ari (Orgs.). Doutrinas essenciais de direito administrativo. vol. 6. São Paulo : RT, 2012, p. 1163-1200. 1115-1133.

PEREIRA, César A. Guimarães. Administração pública e direito do consumidor.In: ARAGÃO, Alexandre Santos de; MARQUES NETO, Floriano de Azevedo (Coords.). Direito administrativo e seus novos paradigmas. Belo Horizonte : Fórum, 2008.

RANIERI, Nina Beatriz Stocco. Autonomia universitária: as universidades públicas e a Constituição Federal de 1988. São Paulo: Imprensa Oficial do Estado de São Paulo, 2013.

TARTUCE, Flavio. Manual de direito civil: volume único. São Paulo : Método, 2011.

WURSTER, Tani Maria. Os serviços públicos e Código de Defesa do Consumidor. Revista de Doutrina da $4^{\text {a }}$ Região TRF. Porto Alegre, n. 14, set., 2006. Disponível em: <HTTP://revistadoutrina.trf4.jus.br/artigos/edicao014/Tani_Wurster.htm>. Acesso em: 27 jan. 2015 . 